\title{
The assessment of management morbidity in children with myelomeningocoele
}

\author{
YC Gan*1, A Williams², D Cochrane1, P Steinbok¹, A Singhal ${ }^{3}$ and B Irwin²
}

\begin{abstract}
Address: ${ }^{1}$ Division of Paediatric Neurosurgery, British Columbia's Children's Hospital, 4480 Oak St, \#K3-159, Vancouver, BC, Canada, ${ }^{2}$ Myelomeningocoele Program, Department of Paediatric Neurosciences, British Columbia's Children's Hospital, 4480 Oak St, \#K3-159, Vancouver, BC, Canada and ${ }^{3}$ Department of Paediatric Neurosciences, British Columbia's Children's Hospital, 4480 Oak St, \#K3-159, Vancouver, BC, Canada

Email: YC Gan* - ycgan1@yahoo.com

* Corresponding author
\end{abstract}

from 50th Annual Meeting of the Society for Research into Hydrocephalus and Spina Bifida Cambridge, UK. 30 August - 2 September 2006

Published: 2I December 2006

Cerebrospinal Fluid Research 2006, 3(SuppI I):S23 doi:10.II86/I743-8454-3-SI-S23

(c) 2006 Gan et al; licensee BioMed Central Ltd.

\section{Background}

Throughout childhood, numerous operative procedures and therapeutic interventions are required to optimise the functional abilities of children with myelomeningocoele. A previous study determined that families sought normal ambulation, continence and cerebral function from intrauterine interventions. Similar goals guide recommendations for treatment and parental consent for post-natal management. The purpose of this paper is to describe the surgical interventions performed, to optimize functional ability, on a cohort of patients with myelomeningocoele during the first 18 years of life.

\section{Materials and methods}

Patients with myelomeningocoele born between 1965 and 1990 and managed through the Spinal Cord Clinic at British Columbia Children's Hospital, Vancouver were reviewed to determine the number and sequence of operative procedures performed during the first 18 years of life. Operative interventions were categorized on the basis of the intent of the procedure to maintain function as follows: 1) Cerebral function (shunt procedures, craniocervical decompression etc), 2) Mobility (spinal neural and orthopaedic procedures, 3) Urinary and faecal continence (urological and general surgical procedures), 4) Other procedures.

\section{Results}

(Preliminary): The cohort totals 207 patients of which 57 patients have been reviewed. Five hundred and eighty-six operations were performed on these 57 patients with a mean of 10.3 operations per person. There were 224 procedures to maintain and optimize cerebral function, 183 operations to optimize mobility, 106 procedures to address urinary and faecal continence. Seventy-three other operations were also performed. Forty-nine patients $(86 \%)$ required shunting for hydrocephalus and to maintain cerebral function, they required an additional 175 procedures; averaging 3.6 procedures per patient. In support of independent mobility, following closure of myelomeningocoele, an average 2.2 spinal neural \& orthopaedic operationswere required per patient. Thirtyone patients required an average of 2.8 urological operations and 8 patients required a mean of 2.4 procedures to achieve urinary and faecal continence. The operations to optimise cerebral function and ambulation tend to happen at the first year of life with at least 50\% occurring in this period. Then it tends to intersperse quite regularly throughout the years. The other procedures usually occur after the first few years and increasing in frequency later on.

\section{Conclusion}

The multidisciplinary management of patients with myelomeningocoele has resulted in significant improvement 
in mortality and functional morbidity achieved through multiple operative interventions. This observational study has enumerated the frequency of surgical procedures performed to maintain or further functional abilities in these children. While further analyses are necessary to determine the efficacy of these procedures, this basic data is useful for counselling families on the impact of management directed to achieve optimal functional ability.

Publish with Bio Med Central and every scientist can read your work free of charge

"BioMed Central will be the most significant development for disseminating the results of biomedical research in our lifetime. " Sir Paul Nurse, Cancer Research UK

Your research papers will be:

- available free of charge to the entire biomedical community

- peer reviewed and published immediately upon acceptance

- cited in PubMed and archived on PubMed Central

- yours - you keep the copyright

Submit your manuscript here:

http://www.biomedcentral.com/info/publishing_adv.asp 